\title{
A method for merging nadir-sounding climate records, with an application to the global-mean stratospheric temperature data sets from SSU and AMSU
}

\author{
C. McLandress ${ }^{1}$, T. G. Shepherd ${ }^{2}$, A. I. Jonsson ${ }^{1}$, T. von Clarmann ${ }^{3}$, and B. Funke ${ }^{4}$ \\ ${ }^{1}$ Department of Physics, University of Toronto, Toronto, Canada \\ ${ }^{2}$ Department of Meteorology, University of Reading, Reading, UK \\ ${ }^{3}$ Institute for Meteorology and Climate Research, Karlsruhe Institute of Technology, Karlsruhe, Germany \\ ${ }^{4}$ Instituto de Astrofísica de Andalucía, CSIC, Granada, Spain
}

Correspondence to: C. McLandress (charles@atmosp.physics.utoronto.ca)

Received: 8 January 2015 - Published in Atmos. Chem. Phys. Discuss.: 2 April 2015

Revised: 1 July 2015 - Accepted: 28 July 2015 - Published: 20 August 2015

\begin{abstract}
A method is proposed for merging different nadirsounding climate data records using measurements from high-resolution limb sounders to provide a transfer function between the different nadir measurements. The two nadirsounding records need not be overlapping so long as the limb-sounding record bridges between them. The method is applied to global-mean stratospheric temperatures from the NOAA Climate Data Records based on the Stratospheric Sounding Unit (SSU) and the Advanced Microwave Sounding Unit-A (AMSU), extending the SSU record forward in time to yield a continuous data set from 1979 to present, and providing a simple framework for extending the SSU record into the future using AMSU. SSU and AMSU are bridged using temperature measurements from the Michelson Interferometer for Passive Atmospheric Sounding (MIPAS), which is of high enough vertical resolution to accurately represent the weighting functions of both SSU and AMSU. For this application, a purely statistical approach is not viable since the different nadir channels are not sufficiently linearly independent, statistically speaking. The near-global-mean linear temperature trends for extended SSU for 1980-2012 are $-0.63 \pm 0.13,-0.71 \pm 0.15$ and $-0.80 \pm 0.17 \mathrm{Kdecade}^{-1}$ ( $95 \%$ confidence) for channels 1, 2 and 3, respectively. The extended SSU temperature changes are in good agreement with those from the Microwave Limb Sounder (MLS) on the Aura satellite, with both exhibiting a cooling trend of $\sim 0.6 \pm 0.3 \mathrm{~K} \mathrm{decade}^{-1}$ in the upper stratosphere from 2004 to 2012. The extended SSU record is found to be in agreement with high-top coupled atmosphere-ocean models over
\end{abstract}

the 1980-2012 period, including the continued cooling over the first decade of the 21 st century.

\section{Introduction}

Stratospheric cooling has long been regarded as a key indicator of two anthropogenic climate forcings (IPCC 2013; WMO, 2014): that from increasing abundances of $\mathrm{CO}_{2}$, and that from the ozone decline associated with the increased abundances of ozone-depleting substances (ODSs). The former has continued secularly, while the latter peaked in the late 1990s and has been slowly declining since then. Thus, the contrast between the early and more recent parts of the stratospheric temperature record is an important fingerprint of anthropogenic influence (Shepherd and Jonsson, 2008). In addition to the anthropogenic influences, stratospheric temperature is also strongly perturbed by the 11-year solar cycle and by volcanic eruptions. As a consequence, the anthropogenic cooling is considerably modulated in time.

In the stratosphere, global-mean temperature is, to a first approximation, unaffected by dynamics and is therefore close to radiative equilibrium (Fomichev, 2009). This makes it an ideal quantity for detection and attribution of anthropogenic influence (Shine et al., 2003). However, global averages are only obtainable from satellites, and the only longterm satellite record of stratospheric temperature is that from the operational nadir sounders, the Stratospheric Sounding 
Unit (SSU)/Microwave Sounding Unit (MSU) and the Advanced Microwave Sounding Unit-A (henceforth AMSU) (Randel et al., 2009), which represent deep atmospheric layers. Note that the vertically resolved temperature data from global positioning system (GPS) radio occultation only begin in the current century (Wickert et al., 2001), and do not reach into the upper stratosphere, where the strongest cooling is found. The nadir-sounding measurements were never designed for climate monitoring, and homogenizing the data from different operational satellites, with rapidly drifting orbits, is a challenge (Wang et al., 2012; Zou et al., 2014; Nash and Saunders, 2015).

In the lower stratosphere, the relevant nadir record is provided by MSU channel 4 (and continued by AMSU channel 9; Christy et al., 2003; Mears and Wentz, 2009) and is supplemented by radiosondes and, since the early 2000s, by GPS radio occultation. The global-mean MSU4 record is considered fairly reliable and most attention has been focused on its latitudinal structure (Randel et al., 2009).

The middle and upper stratosphere is, however, a completely different story. There the nadir record is provided by three SSU channels which began in 1979 and ended in 2006, and by six AMSU channels which began in 2001 and are ongoing. Because the weighting functions of the SSU and AMSU channels are very different, the two records cannot be immediately combined. Moreover, confidence in the SSU record has been low, even for global-mean temperature, because of the lack of corroborative measurements, drift issues within the SSU record itself, and the striking differences identified by Thompson et al. (2012) between the two SSU products available at that time (from the National Oceanic and Atmospheric Administration (NOAA) and the Met Office) and between the measurements and chemistry-climate models.

Normally, differences between measurements and models would tend to cast suspicion on the models, not the measurements. However, because global-mean stratospheric temperature is radiatively controlled, its behaviour in the middle and upper stratosphere, where the radiative processes are well understood, should be reasonably well represented by chemistry-climate models. Indeed, Fig. 2 of Thompson et al. (2012) shows that for the SSU channels the differences in cooling between models and observations, and between the Met Office and NOAA products of the time, are in almost all cases much larger than the inter-model spread. One of the mysteries arising from Thompson et al. (2012) was the apparent lack of continued cooling in the SSU record during the early 2000s, in contrast to the models and in contradiction to physical expectations. Because the SSU record ended in 2005, this mystery was unresolved.

The large differences between the NOAA SSU results and models found by Thompson et al. motivated the development of a revised version of NOAA SSU (version 2), the results of which are published in Zou et al. (2014). The version 2 global-mean temperatures exhibit weaker long-term cool- ing trends than the version 1 temperatures that are shown in Thompson et al. (by $\sim 30 \%$ for channels 1 and 3 and $\sim 17 \%$ for channel 2). Although Zou et al. did not compare their results to models, visual inspection of their version 2 temperatures indicates much closer agreement with the model results shown in Thompson et al. (2012). There has also been a subsequent revision of the Met Office data set (Nash and Saunders, 2015).

In this paper, we propose a method for merging different nadir-sounding climate data records, and apply it to the NOAA SSU and AMSU global-mean stratospheric temperature records. Specifically we use the AMSU data to extend the three SSU channels forward in time, given the paradigmatic importance of that climate data record. We show that a purely statistical approach, using multiple linear regression, is unworkable for this particular application since the six AMSU channels are not sufficiently linearly independent. Instead, we propose a physically based method using limbsounding measurements, with much higher vertical resolution, to accurately represent the weighting functions of both SSU and AMSU and thereby act as a transfer function between the two nadir-sounding data sets. For this purpose we use temperature data from the Michelson Interferometer for Passive Atmospheric Sounding (MIPAS). It is important to emphasize that the merged data set can only be as good as the component data sets going in, and relies on the extensive efforts spent on homogenizing the SSU and AMSU data records themselves.

Since we are dealing with monthly mean, global-mean data, the data are highly averaged and the effect of random measurement errors is expected to be low. Characterization of the systematic errors in such highly averaged quantities in a bottom-up fashion would be extremely challenging (Hegglin et al., 2013). Instead, our approach is to compare the different data sets (after transformation via the weighting functions) over their overlap periods to see whether the differences between them can be characterized in terms of a constant offset (within some noise). If this is the case, then the merging can be done with confidence. Thus, the validity of the approach can be assessed a posteriori. This approach was followed by Hegglin et al. (2014) in constructing a merged stratospheric water vapour record. Solomon et al. (2010) also performed such an additive relative bias correction to merge the Halogen Occultation Experiment (HALOE) and Microwave Limb Sounder (MLS) stratospheric water vapour records. Thus there is ample precedent for such an approach in the literature.

The data sets used are described in Sect. 2. The merging methodology and the comparison between MIPAS and the two nadir-sounding records are provided in Sect. 3.1. This comparison shows that the different global-mean data sets track each other very well, so additive relative biases can be identified with small uncertainties. Section 3.2 examines the (near) global-mean temperature trends, both over the recent record (as represented by the six AMSU channels) where we 
compare the MIPAS and AMSU trends to those from MLS on the Aura satellite, and over the extended SSU record. The extended SSU record is found to be in agreement with hightop coupled atmosphere-ocean models over the 1980-2012 period, including the continued cooling over the first decade of the 21st century. Conclusions are drawn in Sect. 4.

\section{Description of data sets}

\subsection{SSU}

SSU is a three-channel infrared radiometer on board a series of NOAA satellites which measures temperatures over deep layers in the stratosphere. The near-global $\left(\sim 85^{\circ} \mathrm{S}\right.$ to $\left.85^{\circ} \mathrm{N}\right)$ data set extends from 1979 until early 2006. We use version 2 brightness temperatures (Zou et al., 2014), as well as the weighting functions for the three channels. The data set is produced by the NOAA Center for Satellite Applications and Research (STAR) and is available at ftp://ftp.star.nesdis.noaa. gov/pub/smcd/emb/mscat/data/SSU/SSU_v2.0/.

As stated in the Introduction, version 2 was developed primarily as a result of the large differences found between SSU version 1 (Wang et al., 2012) and a Met Office version of SSU, as well as between SSU version 1 and models, that were documented in Thompson et al. (2012). Differences from version 1 include improvements in the radiance calibration and in the adjustments for diurnal drift and intersatellite biases. Please refer to Zou et al. (2014) for an in-depth discussion of the differences.

\subsection{AMSU}

AMSU-A is a microwave radiometer on board a series of recent, current and future NOAA satellites. It has 11 channels, 6 of which (channels 9 to 13) provide coverage in the stratosphere. The instrument was first launched in 1998, although not all of the stratospheric channels were in operation until 2001. We use brightness temperatures analysed by NOAA STAR (Wang and Zou, 2014), which are available at ftp://ftp.star.nesdis.noaa.gov/ $\mathrm{pub} / \mathrm{smcd} / \mathrm{emb} / \mathrm{mscat} / \mathrm{data} / A M S U \_v 1.0 /$ monthly. The corresponding weighting functions for channels 9 to 14 were provided courtesy of Likun Wang of NOAA STAR. The temperature data for channels 9 to 13 start in January 1999; those for channel 14 start 2 years later. As with SSU, the AMSU data extend from $\sim 85^{\circ} \mathrm{S}$ to $85^{\circ} \mathrm{N}$.

\subsection{MIPAS}

MIPAS is a limb sounder which measured infrared emission from which vertical profiles of temperature and atmospheric constituents are derived (Fischer et al., 2008). We use zonal and monthly mean gridded temperatures computed from versions V3o_T_10 and V5r_T220 for the periods 20022004 and 2005-2011, respectively. These data are available at http://www.esa-spin.org/index.php/spin-data-sets and are provided on a $5^{\circ}$ latitude grid from $\sim 75^{\circ} \mathrm{S}$ to $75^{\circ} \mathrm{N}$ with 28 pressure levels ranging from 300 to $0.1 \mathrm{hPa}$. The parent data were produced by the Institute for Meteorology and Climate Research at Karlsruhe Institute of Technology, in cooperation with the Institute of Astrophysics of Andalusia, from calibrated radiance spectra provided by the European Space Agency. The MIPAS temperature retrieval method is discussed in von Clarmann et al. (2003) for the high-spectralresolution measurement period until 2004 and in von Clarmann et al. (2009) for the reduced spectral resolution measurement period from 2005 onwards. MIPAS temperatures have been validated by Wang et al. (2005) and Stiller et al. (2012).

\subsection{MLS}

Aura MLS is a limb sounder that measures thermal microwave emission. It has provided a nearly continuous set of measurements of temperature and trace gases in the middle atmosphere since August 2004. The data extend near globally and from the middle troposphere to the lower thermosphere. We use version 3.3 temperature data (Livesey et al., 2011) through to the end of 2011. The temperature retrieval method and validation are discussed in Schwartz et al. (2008).

\subsection{CMAM30}

The CMAM30 data set, which extends from 1979 to 2011, is produced using a specified-dynamics version of the Canadian Middle Atmosphere Model (CMAM) that is driven by winds and temperatures from the interim version of the European Centre for Medium-Range Weather Forecasts Reanalysis (ERA Interim; Dee et al., 2011), where the global-mean temperatures have been adjusted in the upper stratosphere to remove temporal discontinuities in 1985 and 1998 that have arisen from the introduction of new satellite data in the assimilation process (McLandress et al., 2014). Here we use the monthly mean CMAM30 temperatures, which are available at http://www.cccma.ec.gc.ca/data/ cmam/output/CMAM/CMAM30-SD/mon/atmos/.

\subsection{CMIP5}

Coupled atmosphere-ocean models from phase 5 of the Coupled Model Intercomparison Project (CMIP5) are also examined. Most of these models are not chemistry-climate models and do not have upper boundaries extending high into the stratosphere or above. The nine models that are used are listed in Table 1. To span the period extending from 1979 to 2012, data from the historical experiment (ending December 2005) and the Representative Concentration Pathway (RCP) 4.5 experiment (a projection starting in January 2006) are employed. Since the RCP 4.5 simulations use as initial conditions data from the end of the historical simulations, the 
Table 1. CMIP5 models used in this study. The number of ensemble members for the historical and RCP 4.5 experiments are listed in the second and third columns, respectively. The fourth column lists the SSU channels onto which the data are projected, which is determined by the height of the top data level: channel 1 (any model with data at $1 \mathrm{hPa}$ ), channels 1 and 2 (any model with data at pressure levels below $1 \mathrm{hPa}$ ), and channels $1-3$ (any model with data at pressure levels below $0.1 \mathrm{hPa}$ ).

\begin{tabular}{lccr}
\hline Model & Historical & RCP 4.5 & SSU channels \\
\hline CanESM2 & 1 & 5 & 1 \\
GFDL-CM3 & 5 & 1 & 1 \\
HadGEM2-CC & 3 & 1 & 1,2 \\
MIROC4h & 3 & 3 & 1 \\
MIROC-ESM & 3 & 3 & $1,2,3$ \\
MIROC-ESM-CHEM & 1 & 9 & $1,2,3$ \\
MPI-ESM-LR & 3 & 3 & $1,2,3$ \\
MPI-ESM-P & 2 & 0 & $1,2,3$ \\
MRI-CGCM3 & 5 & 1 & $1,2,3$ \\
\hline
\end{tabular}

two simulations for a given model are continuous and, thus, can be simply concatenated to produce a single time series. Since we use only the first few years of the RCP 4.5 simulation, differences between it and the three other RCP simulations (RCP 2.5, 6 and 8.5) are expected to be very small. Following Thompson et al. (2012) the SSU channels onto which the data are projected depend on the height of the top model data level: channel 1 (any model with data at $1 \mathrm{hPa}$ ), channels 1 and 2 (any model with data at pressure levels below $1 \mathrm{hPa}$ ), and channels 1-3 (any model with data at pressure levels below $0.1 \mathrm{hPa}$ ).

\subsection{CCMVal2}

Chemistry-climate model (CCM) simulations of the recent past from phase 2 of the Chemistry-Climate Model Validation (CCMVal2) project are used. These REF-B1 simulations use observed sea-surface temperatures and sea-ice distributions and observed forcings (volcanic aerosols, tropospheric concentrations of greenhouse gases, ozone-depleting substances, and solar variations). The data are available at the SPARC Data Center at http://www.sparc-climate. org/data-center/data-access/. The following 16 models, all with model tops above $1 \mathrm{hPa}$, were used: AMTRAC3, CCSRNIES, CMAM, CNRM-ACM, EMAC, EMAC-FUB, GEOSCCM (and hist-GEOSCCM), LMDZrepro, MRI, Niwa-SOCOL, SOCOL, ULAQ, UMETRAC, UMUKCAMETO, UMUKCA-UCAM and WACCM; these model acronyms are defined in Morgenstern et al. (2010). Two models (CAM3.5 and E39C) were excluded because their upper boundaries were at pressures above $1 \mathrm{hPa}$. A third model (UMSLIMCAT) was excluded because the file containing the zonal and monthly mean temperature data did not have a latitude array. For model data sets containing a missing data flag for points below ground, those points were filled using tem- peratures from the first good data point above. Since such points occur at high latitudes (Antarctica) and at pressure levels corresponding to altitudes far below the peak of the SSU weighting functions, their impact on the SSU-weighted near-global mean is negligible. The CCMVal2 models are described in Morgenstern et al. (2010).

\section{Results}

This section is divided into two parts. The first part (Sect. 3.1) pertains to the merging of the SSU and AMSU data sets. Since this is achieved using MIPAS data as a transfer function, we begin by demonstrating that MIPAS is in good agreement with SSU and AMSU. We then describe the algorithm used to merge SSU and AMSU, and present the merged results. The second part (Sect. 3.2) is an analysis of temperature trends for the post-2000 time period when the AMSU, MIPAS and MLS data are all available, as well as a comparison of our "extended" SSU results to other longterm data sets, including models. All results presented here are for monthly and near-global means $\left(75^{\circ} \mathrm{S}\right.$ to $\left.75^{\circ} \mathrm{N}\right)$. This particular latitude range is dictated by the use of the MIPAS data in merging the SSU and AMSU data sets.

\subsection{Merging SSU and AMSU}

\subsubsection{Comparisons to MIPAS}

In order to compare MIPAS to SSU and AMSU, the MIPAS temperatures must be averaged in the vertical using the SSU and AMSU weighting functions, which are shown in the left and right panels of Fig. 1, respectively (thick solid curves). For simplicity we follow Thompson et al. (2012) in using fixed weighting functions, rather than attempting to account for possible state dependence. The three SSU weighting functions (channels 1-3) peak at approximately $\sim 30,39$ and $44 \mathrm{~km}$. The six stratospheric AMSU weighting functions (channels 9-14) peak at $\sim 17,20,25,30,37$ and $42 \mathrm{~km}$. The other curves in the left panel of Fig. 1 will be discussed in due course.

The vertical averaging is performed on a log-pressure height grid, with the limits of integration being the corresponding height range of the MIPAS data: $300 \mathrm{hPa}$ $(\sim 8.4 \mathrm{~km})$ and $0.1 \mathrm{hPa}(\sim 64.5 \mathrm{~km})$. The vertically averaged temperature for channel $n$ (denoted $T_{n}$ ) is therefore given by

$T_{n}(t)=\int_{z b}^{z_{t}} T(t, z) W_{n}(z) \mathrm{d} z$,

where $t$ is time in months and $z$ is the log-pressure height [ $z=-H \ln \left(p / p_{s}\right)$, with $H=7 \mathrm{~km}$ and $p_{s}=1000 \mathrm{hPa}$ ], and $z_{b}$ and $z_{t}$ are the limits of integration, namely $z(300 \mathrm{hPa})$ and $z(0.1 \mathrm{hPa})$. Before computing the vertical average, the weighting functions are normalized so that their vertical integral from $z_{b}$ to $z_{t}$ equals 1 . 

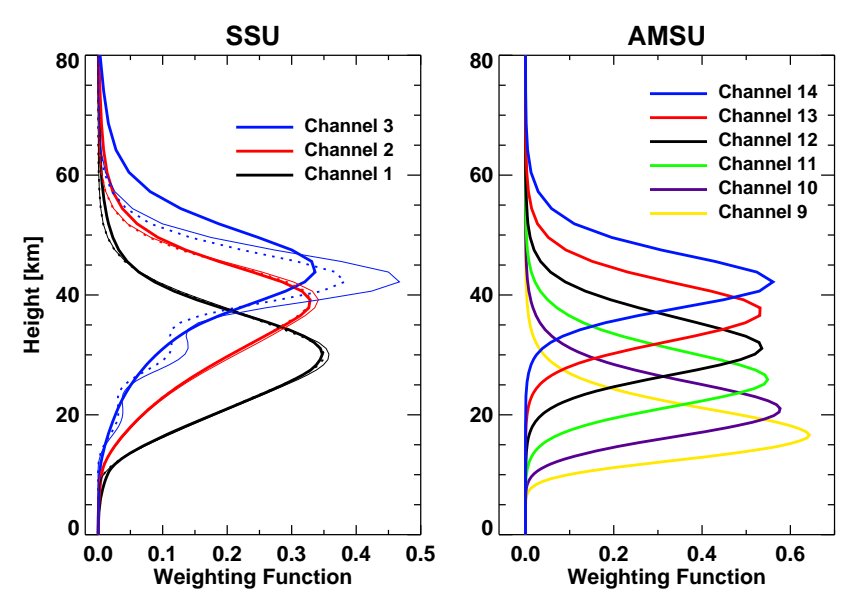

Figure 1. Vertical weighting functions (thick solid curves) for SSU (left) and AMSU (right). The thin solid and dotted curves in the left panel are, respectively, the normalized and unnormalized fits to the SSU weighting functions obtained using the AMSU weighting functions using Eq. (3); see text for details.

By excluding the lower troposphere and upper mesosphere in Eq. (1), the full vertical integrals of the weighting functions are approximated. This approximation is less accurate for SSU than it is for AMSU since the SSU weighting functions extend down lower and up higher than for AMSU (Fig. 1). To investigate the possible impact of this incomplete vertical averaging using the SSU weighting functions, we first filled the MIPAS temperature data below $300 \mathrm{hPa}$ and above $0.1 \mathrm{hPa}$ using the corresponding CMAM30 data, and then performed the integration using $z_{b}=0 \mathrm{~km}$ to $z_{t} \cong 100 \mathrm{~km}$. The resulting vertically averaged temperatures for the three SSU channels (not shown) are virtually indistinguishable from those obtained by averaging only over the MIPAS domain $(8-65 \mathrm{~km})$, leading us to conclude that the effect of the incomplete vertical sampling of the integral given by Eq. (1) is negligible.

Figure 2 compares the SSU-weighted MIPAS temperatures to SSU for 2002-2007, the years when the two instruments overlap. The thick and thin lines denote, respectively, the results with and without the seasonal cycle included, where the seasonal cycle is given by the first three harmonics of the annual cycle. The MIPAS time series have each been offset by a constant amount with respect to SSU, with the offset being determined so that the mean difference between the deseasonalized MIPAS and SSU time series is zero over the 4-year overlap period. The offsets are small: $\sim-0.2 \mathrm{~K}$ for channels 1 and 3 and $\sim-0.7 \mathrm{~K}$ for channel 2 . There is very good agreement between MIPAS and SSU for the seasonal cycle; however, as will be discussed later, the MIPAS data exhibit a larger trend than does SSU (see Fig. 9).

Figure 3 shows the corresponding results for AMSU and AMSU-weighted MIPAS. As in Fig. 2, the MIPAS results are offset with respect to AMSU, with the magnitude of the off-
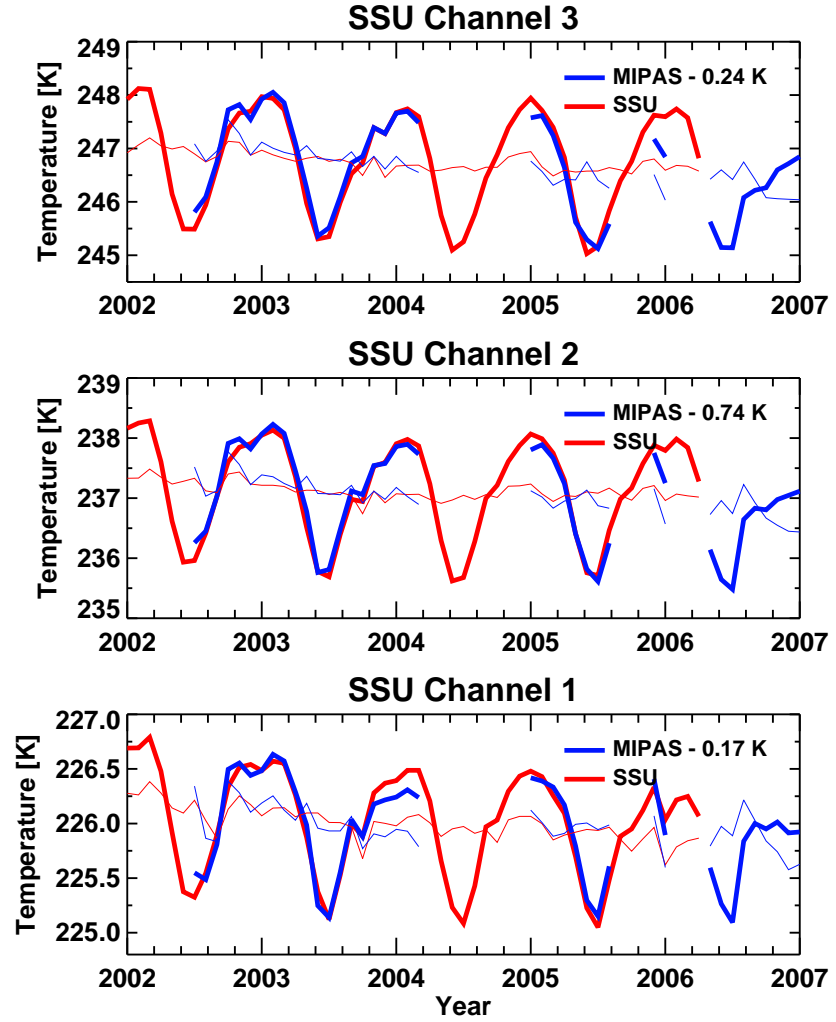

Figure 2. SSU (red) and SSU-weighted MIPAS (blue) temperatures for channels 1-3. The thin curves are the deseasonalized temperatures. The weighted MIPAS temperatures are offset by a constant amount so that the mean difference between the deseasonalized SSU and MIPAS time series is zero; the value of this offset is labelled in each panel. In this and all other figures, monthly and nearglobal $\left(75^{\circ} \mathrm{S}\right.$ to $\left.75^{\circ} \mathrm{N}\right)$ means are shown, and the tick marks directly above each year label on the horizontal axes are for January of that year.

sets again all being less than $1 \mathrm{~K}$. As seen with SSU, there is very good agreement between MIPAS and AMSU for the seasonal cycle, but with MIPAS exhibiting stronger cooling in the upper three channels (12-14). We will discuss this trend difference in Sect. 3.2 when we compare the trends to MLS.

\subsubsection{Algorithm for merging SSU and AMSU}

Since the SSU and AMSU weighting functions differ in shape and height of the maxima, the two data sets must be combined by taking suitably weighted averages of the different channel temperatures. One way this might be done would be purely statistically, fitting the deseasonalized temperatures of instrument $A$ to instrument $B$ using multiple linear regression as follows:

$\hat{T}_{n}^{\mathrm{A}}(t)=\sum_{m=m_{1}}^{m_{2}} \alpha_{m} T_{m}^{\mathrm{B}}(t)$ 
where $\hat{T}_{n}^{\mathrm{A}}$ (with the hat) denotes the fitted deseasonalized temperature from channel $n$ of instrument $\mathrm{A}, T_{m}^{\mathrm{B}}$ denotes the actual deseasonalized temperature from channel $m$ of instrument $\mathrm{B}$, and the constants $\alpha_{m}$ are the coefficients determined using a least-squares fit. However, this method, which we shall refer to as the temperature-fit method, is problematic because the time series used in computing the fit $\left(T_{m}^{\mathrm{B}}\right)$ are highly linearly dependent, as is shown in Fig. 4 in the case where $\mathrm{B}=\mathrm{AMSU}$. The top panel shows the deseasonalized temperature anomalies for the six channels superimposed. Adjacent or near-adjacent channels are highly correlated. Given the overlap in the AMSU weighting functions $(W)$, some correlation is to be expected. For example, for the highest three channels, the overlap between $W_{13}$ and $W_{14}$ is $\sim 61 \%$, between $W_{12}$ and $W_{13}$ it is $\sim 60 \%$ and between $W_{12}$ and $W_{14}$ it is $\sim 31 \%$. However, the fact that the correlations are actually close to unity for those pairs of channels, i.e. $r(13,14) \sim 0.96, r(12,13) \sim 0.96$ and $r(12,14) \sim 0.88$, suggests that they also reflect strong vertical relationships in the variability of global-mean temperature. A similarly high correlation of 0.91 is found between channels 9 and 10 , while channel 11 is highly correlated with both channel 10 $(r \sim 0.90)$ and channel $12(r \sim 0.87)$. Thus, there appear to be only two degrees of freedom among the six channels, representing the upper stratosphere and the lower stratosphere. Similarly high correlations are found, albeit with more noise, in the CMAM30 data shown in the bottom panel of Fig. 4, which is plotted over the 1979 to 2011 period. The high correlations between the different channel temperatures means that the system of equations defined by Eq. (2) is highly underconstrained, and that there are no unique values of the coefficients $\alpha_{m}$. This was verified in a calculation in which one of the $\alpha_{m}$ 's was specified and the remaining ones were computed, which yielded an almost identical temperature time series yet with very different coefficients. For this reason the temperature-fit method will not be used.

An alternative method, which is the method we have adopted, is to determine the fit coefficients from the weighting functions. Such a method has also been examined by the Remote Sensing Systems group, which has processed and combined the SSU data (C. Mears, personal communication, 2014). Using the weighting functions to generate the temperature fit coefficients makes physical sense since it is the channels of instrument $B$ that have weighting functions peaking closer to the peak of a given weighting function of instrument $\mathrm{A}$ that should be given the most weight in the fit. Another advantage of this method is that it does not require the two temperature data sets to overlap in time, as does the temperature-fit method.

The weighting function fit method proceeds as follows. We first express the channel- $n$ weighting function of instrument $A$ as a linear combination of the weighting functions of instrument B:

$\hat{W}_{n}^{\mathrm{A}}(z)=\sum_{m=m_{1}}^{m_{2}} \beta_{m} W_{m}^{\mathrm{B}}(z)$,
Table 2. Unnormalized coefficients $\beta_{m}$ for AMSU channels $m=9-$ 14 of the fits to the three SSU weighting functions $n=1-3$ used in Eq. (3).

\begin{tabular}{rccr}
\hline $\begin{array}{r}\text { AMSU } \\
\text { channel }(\mathrm{m})\end{array}$ & SSU $(n=1)$ & SSU $(n=2)$ & SSU $(n=3)$ \\
\hline 14 & 0.018 & 0.313 & 0.786 \\
13 & 0.114 & 0.300 & -0.267 \\
12 & 0.422 & 0.185 & 0.334 \\
11 & 0.226 & 0.100 & -0.117 \\
10 & 0.146 & 0.048 & 0.098 \\
9 & 0.053 & 0.021 & -0.017 \\
\hline
\end{tabular}

where the hat denotes the fitted weighting function. The constants $\beta_{m}$ are computed using least squares and are normalized so that $\sum_{m=m_{1}}^{m_{2}} \beta_{m}=1$. The deseasonalized temperatures for channel $n$ of instrument $\mathrm{A}$ are then constructed as follows:

$\hat{T}_{n}^{\mathrm{A}}(t)=c_{n}+\sum_{m=m_{1}}^{m_{2}} \beta_{m} T_{m}^{\mathrm{B}}(t)$,

where the constants $c_{n}$ represent an additive relative bias between the two measurements.

The dotted curves in the left panel of Fig. 1 are the fits to the three SSU weighting functions using the six AMSU weighting functions ( $m_{1}=9$ and $\left.m_{2}=14\right)$, computed using Eq. (3), but before the $\beta_{m}$ 's are normalized. The values of the unnormalized $\beta_{m}$ 's are given in Table 2 . The reason that they do not sum to unity is due to incomplete sampling of the target weighting function. As seen in Fig. 1 the fits to SSU channels 1 and 2 are excellent, with the only significant departures from the true weighting function occurring below $\sim 10 \mathrm{~km}$ and above $\sim 50 \mathrm{~km}$, where the SSU weighting functions do not have much strength anyway. Not surprisingly, the fit is poorest for the upper SSU channel 3 since there are no AMSU weighting functions that peak above it. The corresponding fits using the normalized $\beta_{m}$ 's are given by the thin solid curves.

The reason for normalizing the $\beta_{m}$ 's becomes apparent by considering the case of a constant temperature $T_{o}$ profile with an assumption of no relative bias between instruments $A$ and $\mathrm{B}$, in which case it can be easily shown that

$c_{n}=T_{o}\left(1-\sum_{m=m_{1}}^{m_{2}} \beta_{m}\right)$.

Since we have assumed no relative bias between the two instruments, $c_{n}$ should vanish. This will only occur if $\sum_{m=m_{1}}^{m_{2}} \beta_{m}=1$.

To compute $c_{n}$ we use temperatures from a third instrument (C), which overlaps in time with instruments A and B and is of high enough vertical resolution that a sufficiently accurate representation of the temperatures obtained from the weighting functions of both instruments $\mathrm{A}$ and $\mathrm{B}$ can be computed. In this case, instrument $C$ provides a transfer function between instruments B and A, whereby $c_{n}$ can be expressed as 

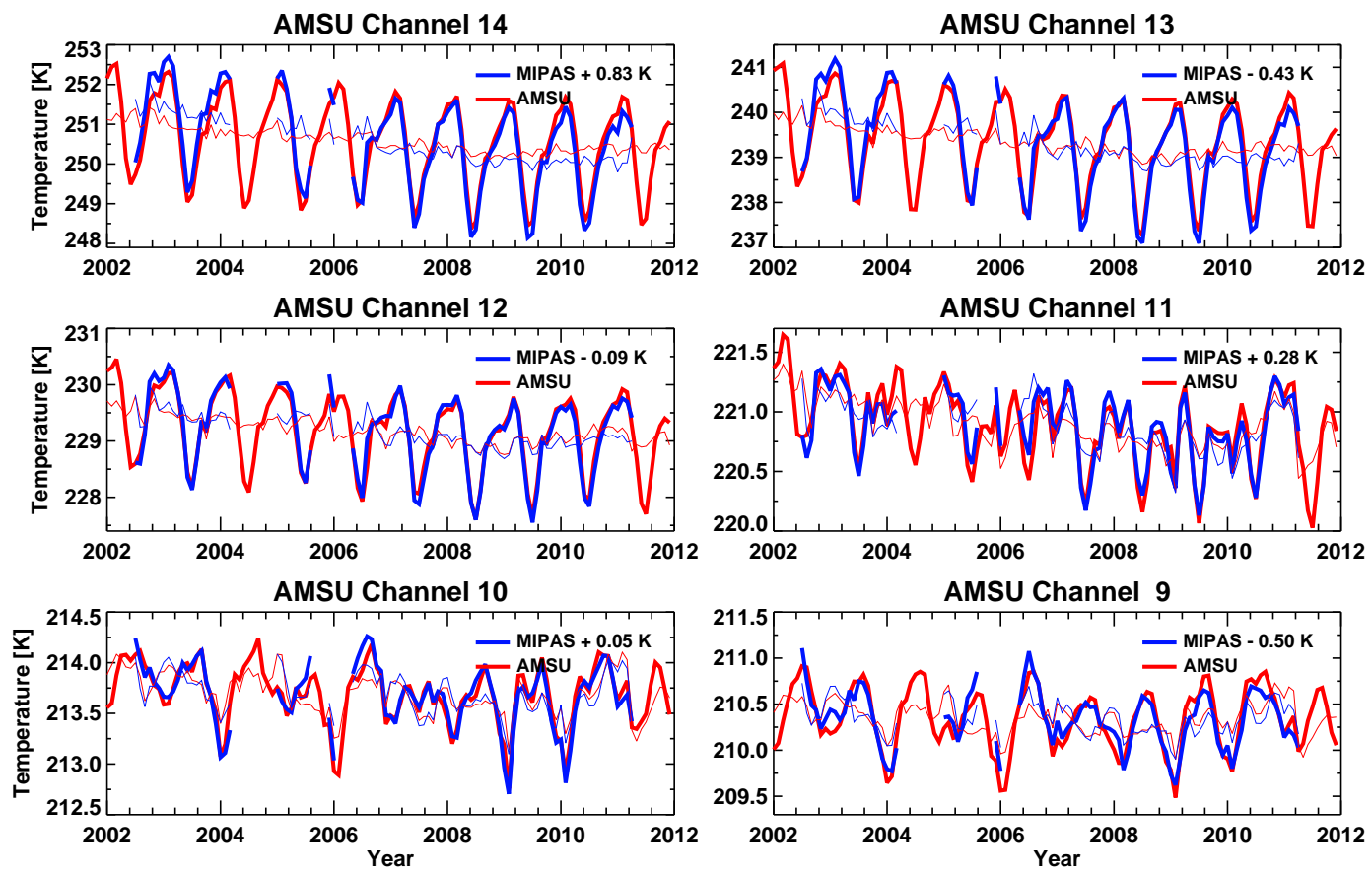

Figure 3. AMSU (red) and AMSU-weighted MIPAS (blue) temperatures for channels 9-14. The thin curves denote the deseasonalized temperatures. See the Fig. 2 caption for more details.

the sum of three biases, namely

$c_{n}=E_{\mathrm{A}-\mathrm{C}}+E_{\mathrm{C}-\mathrm{B}}+E_{W}$,

where

$E_{\mathrm{A}-\mathrm{C}} \equiv\left\langle T^{\mathrm{A}}\right\rangle-\left\langle T^{\mathrm{AC}}\right\rangle$,

$E_{\mathrm{C}-\mathrm{B}} \equiv \sum_{m} \beta_{m}\left[\left\langle T_{m}^{\mathrm{BC}}\right\rangle-\left\langle T_{m}^{\mathrm{B}}\right\rangle\right]$,

$E_{W} \equiv\left\langle T^{\mathrm{AC}}\right\rangle-\sum_{m} \beta_{m}\left\langle T_{m}^{\mathrm{BC}}\right\rangle$,

where the angle brackets denote a time average, and, as before, all temperatures are deseasonalized. For clarity, we have omitted the subscript $n$ since it is common to all terms. The quantities $T^{\mathrm{AC}}$ and $T^{\mathrm{BC}}$ denote the temperatures of instrument $C$ that have been averaged in the vertical using the weighting functions for instruments $\mathrm{A}$ and $\mathrm{B}$, respectively. The first term $\left(E_{\mathrm{A}-\mathrm{C}}\right)$ in Eq. (6) denotes the relative bias between the temperature of instrument $\mathrm{A}$ and the instrument A-weighted temperature of instrument $\mathrm{C}$. The second term $\left(E_{\mathrm{C}-\mathrm{B}}\right)$ is the same but for instrument $\mathrm{B}$ (with a minus sign), where the summation over $m$ is required since we are computing the temperature bias for channel $n$ of instrument A. The third term $\left(E_{W}\right)$ is the weighting function bias, which accounts for the error in the fits to the weighting functions; this term must be evaluated using the height-dependent temperatures from instrument $\mathrm{C}$. If the period over which the time averages of the different terms in Eq. (6) are computed is the same, then

$c_{n}=\left\langle T^{\mathrm{A}}\right\rangle-\sum_{m=m_{1}}^{m_{2}} \beta_{m}\left\langle T_{m}^{\mathrm{B}}\right\rangle$,

in which case instrument $\mathrm{C}$ is not needed. The advantage of Eq. (6) over Eq. (10), however, lies in the fact that instrument $\mathrm{C}$ enables us to separate the relative biases into different components. Moreover, if there is a gap in time between instruments $\mathrm{A}$ and $\mathrm{B}$, but instrument $\mathrm{C}$ still overlaps with instruments A and B, then Eq. (10) could not be used.

\subsubsection{Merging SSU and AMSU using MIPAS}

Here we consider only the case where we extend SSU forward in time, which means that $\mathrm{A}=\mathrm{SSU}$ and $\mathrm{B}=\mathrm{AMSU}$ in Eq. (4). While it is certainly possible to extend AMSU backward (i.e. $\mathrm{A}=\mathrm{AMSU}$ and $\mathrm{B}=\mathrm{SSU}$ ), we do not do so because the weighting function bias terms $\left(E_{W}\right)$ are substantially larger when fitting the three broad SSU weighting functions to the six narrower AMSU weighting functions.

Table 3 shows the different bias terms given in Eq. (6), which are used to compute $c_{n}$ in Eq. (4). The bottom row lists the sum of the three biases, which are the $c_{n}$ 's. The magnitudes of the individual bias terms are all less than $1.2 \mathrm{~K}$, with some cancellation between the different terms. The $E_{\text {SSU-MIPAS }}$ term is identical to the offsets between SSU and SSU-weighted MIPAS shown in Fig. 2. The weighting function term $E_{W}$ is largest for channel 3 since the fit is the poorest (see Fig. 1). Figure 5 shows the difference between the deseasonalized SSU temperatures and the fitted tempera- 

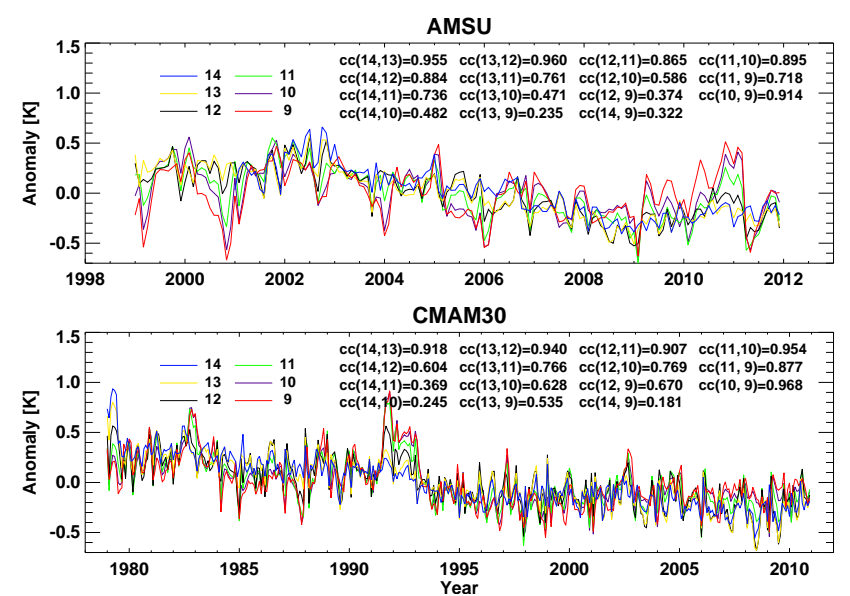

Figure 4. Top: deseasonalized AMSU temperature anomalies with respect to the 1999-2011 mean for channels 9 to 13 and the 2001-2011 mean for channel 14, with the variance of each channel normalized to $0.25 \mathrm{~K}^{2}$. Bottom: same but for AMSU-weighted CMAM30 for the 1979 to 2011 time period. The correlation coefficient between the different channels is labelled in each panel.
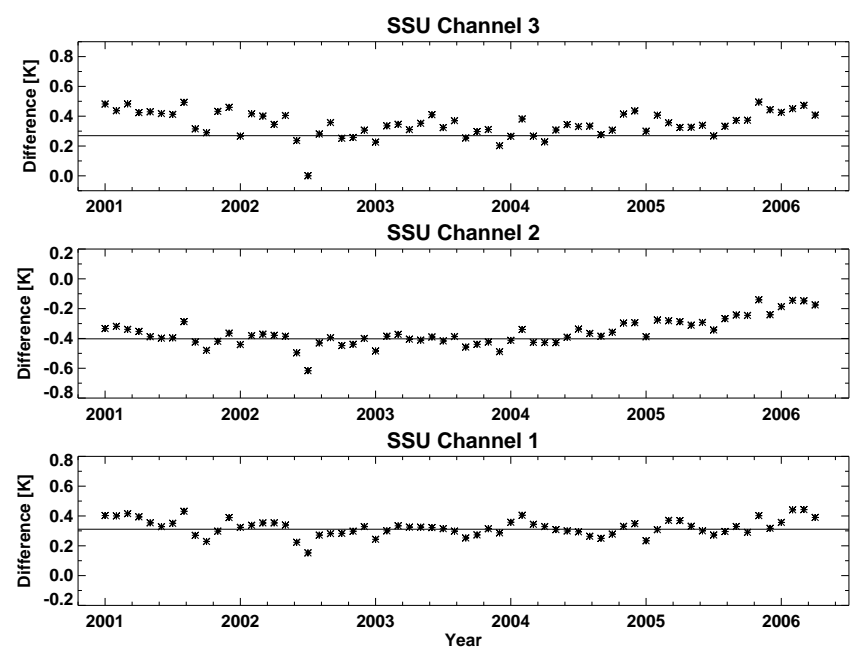

Figure 5. Difference between the deseasonalized SSU temperatures and the fitted temperatures computed using AMSU, i.e. $T_{n}^{\mathrm{SSU}}-$ $\sum_{m=m_{1}}^{m_{2}} \beta_{m} T_{m}^{\mathrm{AMSU}}$. The horizontal lines are the constants $c_{n}$ used in Eq. (4). See text for more details.

tures computed using AMSU as a function of time, and indicates that the relative biases (whose means are the $c_{n}$ 's) are fairly stable in time. The standard deviations of the differences, which provide a conservative measure of the uncertainty of the fits, are $0.06,0.09$ and $0.09 \mathrm{~K}$ for channels 1 , 2 and 3 , respectively. These values are clearly much smaller than the dynamic range seen in Fig. 6, which shows the SSU data (black) and the corresponding extension derived from AMSU and MIPAS using Eqs. (4) and (6) for the 1979-2012 time period. These fit uncertainties have been propagated into our trend uncertainties; the effects are small although
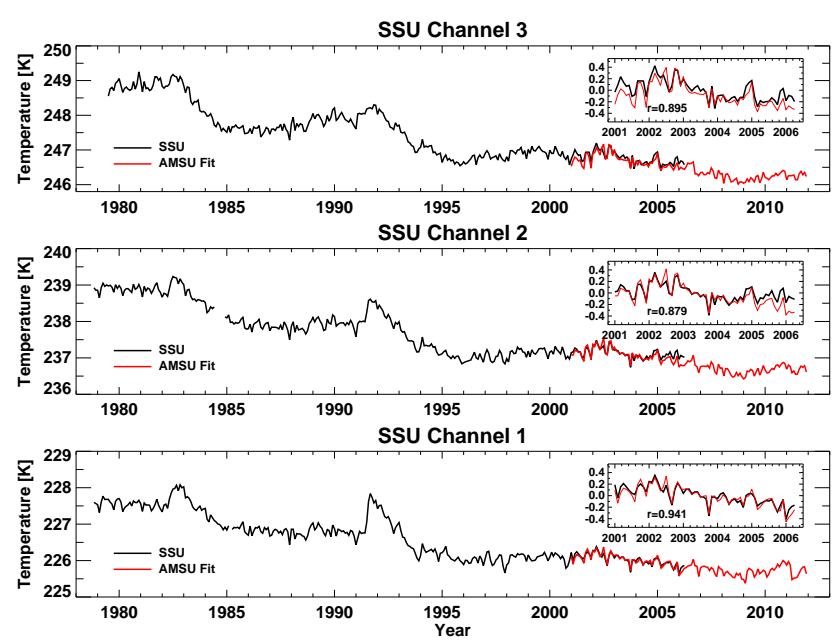

Figure 6. Deseasonalized temperatures for SSU channels 1-3 (black) and the fits computed from AMSU (red) using Eqs. (4) and (6). The insets show blow-ups of the time series in the overlap period (with the SSU time means subtracted off), along with the correlation coefficients $(r)$ between each pair of curves.
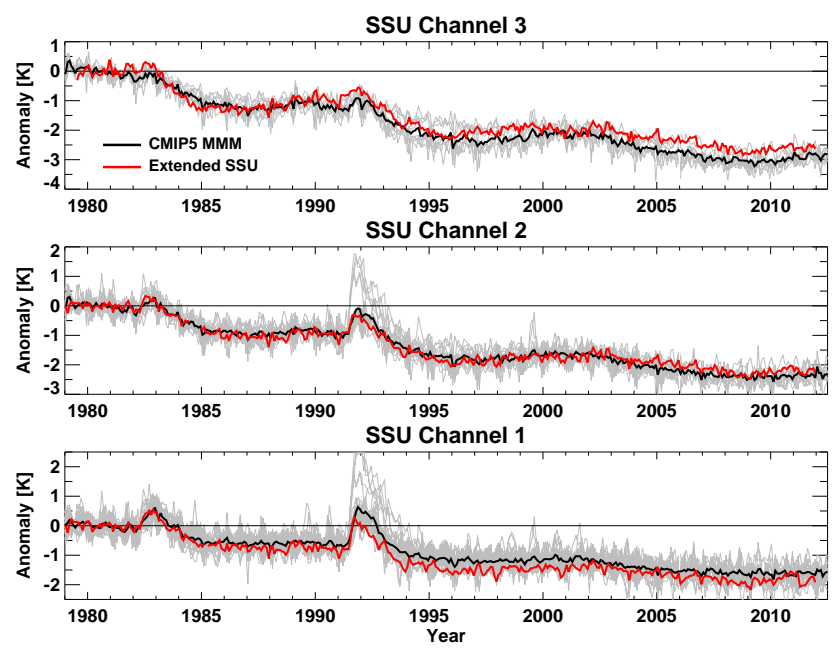

Figure 7. Deseasonalized temperature anomalies for extended SSU (red) and the CMIP5 multi-model mean (black). The light-grey curves are the time series of the individual CMIP5 models used to compute the multi-model mean. Anomalies are computed with respect to 1979-1982; thus the time mean anomaly over this period is zero.

not entirely negligible for the 1980-2012 period. The insets show blow-ups of the two time series in the overlap period, along with the corresponding correlation coefficients $r$. The agreement between the two time series is very good, with the highest correlation occurring for the lowest channel. Even for channel 3, where the fit to the weighting function is the poorest, the correlation coefficient is 0.895 , which suggests that the global-mean temperature variations in this region are vertically coherent. 
Table 3. The three bias terms in the expression for $c_{n}$ in Eq. (6) for $n=1-3$ in the case where instrument $\mathrm{A}=\mathrm{SSU}, \mathrm{B}=\mathrm{AMSU}$ and $\mathrm{C}=$ MIPAS. Units are $\mathrm{K}$. The sum of the terms, which is listed in the bottom row, is the constant $c_{n}$ used in Eq. (4). See text for details.

\begin{tabular}{lrrr}
\hline Bias & SSU $(n=1)$ & SSU $(n=2)$ & SSU $(n=3)$ \\
\hline$E_{\text {SSU-MIPAS }}$ & -0.173 & -0.744 & -0.241 \\
$E_{\text {MIPAS-AMSU }}$ & 0.087 & 0.007 & -0.686 \\
$E_{W}$ & 0.398 & 0.334 & 1.196 \\
Sum $\left(c_{n}\right)$ & 0.312 & -0.403 & 0.269 \\
\hline
\end{tabular}

The SSU and fitted SSU deseasonalized temperature time series can be combined into a single time series, which we shall refer to as the "extended SSU" time series $\widetilde{T}_{n}^{\text {SSU }}$ (denoted with a tilde), as follows:

$\widetilde{T}_{n}^{\mathrm{SSU}}=\alpha(t) T_{n}^{\mathrm{SSU}}+\beta(t) \hat{T}_{n}^{\mathrm{SSU}}$,

where $\hat{T}_{n}^{\mathrm{SSU}}$ is the time series computed using Eqs. (4) and (6), and the time-dependent coefficients $\alpha$ and $\beta$ are given by

$\alpha(t)=1$ for $t \leq t_{1}$

$\alpha(t)=1-\frac{\left(t-t_{1}\right)}{\left(t_{2}-t_{1}\right)}$ for $t_{1} \leq t \leq t_{2}$

$\alpha(t)=0$ for $t \geq t_{2}$

and $\beta=1-\alpha$, where $t_{1}=2001.00$ and $t_{2}=2006.25$ are the start and end dates of the overlap period between SSU and AMSU channel 14. The extended SSU temperatures, expressed as anomalies with respect to the 1979-1982 mean, are shown in Fig. 7 (red curves). The other curves in this figure will be discussed in the next section.

\subsection{Stratospheric temperature trends}

In this section we take a closer look at the temperature trends in the first decade of this century using not only the AMSU and MIPAS data but also MLS. We then take a step back and re-examine the long-term trends in the context of model simulations.

Figure 8 compares AMSU temperatures (black) to the AMSU-weighted results computed from MIPAS (blue) and MLS (red), with the latter two being offset with respect to AMSU for display purposes. The offsets are computed so that the time means in the overlap period are identical to those of AMSU. As remarked earlier, the AMSU-weighted MIPAS temperatures exhibit stronger cooling in the upper channels than do AMSU. MIPAS is known to have a drift due to time-dependent detector nonlinearity, which had not been considered for the calibration of radiance spectra used here (e.g. Eckert et al., 2014). A latitude- and altitude-dependent drift of MIPAS temperatures relative to MLS of the order of $-1 \mathrm{~K} \mathrm{decade}^{-1}$ has been identified for most parts of the stratosphere (Eckert, 2012), which is in agreement with the trend differences found here. A refined calibration, which takes the time dependence of the detector nonlinearity into account, is currently under investigation. The MLS results, however, do not show such an effect, and are in fact in better agreement with AMSU on a year-to-year basis.

The temperature trends from MIPAS and MLS computed from 2004 to 2012 are shown in Fig. 9 as a function of height. Two types of uncertainties are shown. The first assumes the data points are independent (thick error bars and dark shading); this is appropriate when comparing trends between different data sets over the same time period, where the differences will be mainly instrumental. The second takes into account serial correlation using the lag-1 autocorrelation coefficient to estimate the reduced number of degrees of freedom following Santer et al. (2000) (thin error bars and light shading). Since serial correlation is a property of the atmosphere, not of a particular instrument, the lag-1 autocorrelation coefficient computed from the MLS data is used in calculating the reduced number of degrees of freedom for the sparser MIPAS data. Although the time period is relatively short, global-mean temperature exhibits limited internal variability (since it is under radiative control) and so the uncertainties in the trends in the upper stratosphere are relatively low. Superimposed in Fig. 9 are the AMSU trends (black circles) and the AMSU-weighted MLS and MIPAS trends (black squares). The weighted trends are seen to lie along a vertically smoothed version of the profile trends. As was seen in Fig. 8, the agreement between MLS and AMSU is excellent (left panel), while MIPAS shows substantially stronger cooling trends in the upper stratosphere (right panel). The same conclusions can be inferred from the trends from extended SSU (red circles) and SSU-weighted MLS and MIPAS (red squares), computed for the 2004-2012 period, which are also shown in Fig. 9.

Although MLS uses as its a priori an analysis that has assimilated AMSU radiances, the impact of AMSU on the MLS temperatures is thought to be relatively small since the MLS retrievals are more susceptible to vertical variations much shorter than the widths of the AMSU weighting functions (M. Schwartz, personal communication, 2014). We therefore believe that the good agreement between MLS and AMSU is real and therefore an independent validation of the MLS data, while the strong cooling in the MIPAS data is attributed to its known drift. It is not clear whether the zig-zag vertical structure seen in the MLS profile trends is real, and we note that the model trends (cf. Fig. 10) do not exhibit such a structure.

We now return to Fig. 7, which shows the extended SSU temperature anomalies (with respect to 1979-1982) plotted from 1979 to 2012, along with those from the CMIP5 models. Near-global-mean model temperatures are constructed from monthly means and vertically averaged using the SSU weighting functions using Eq. (1), with the limits of integrations being $z_{b}=0 \mathrm{~km}$ and $z_{t}=$ the height corresponding to the top pressure level provided by each model data file, nor- 

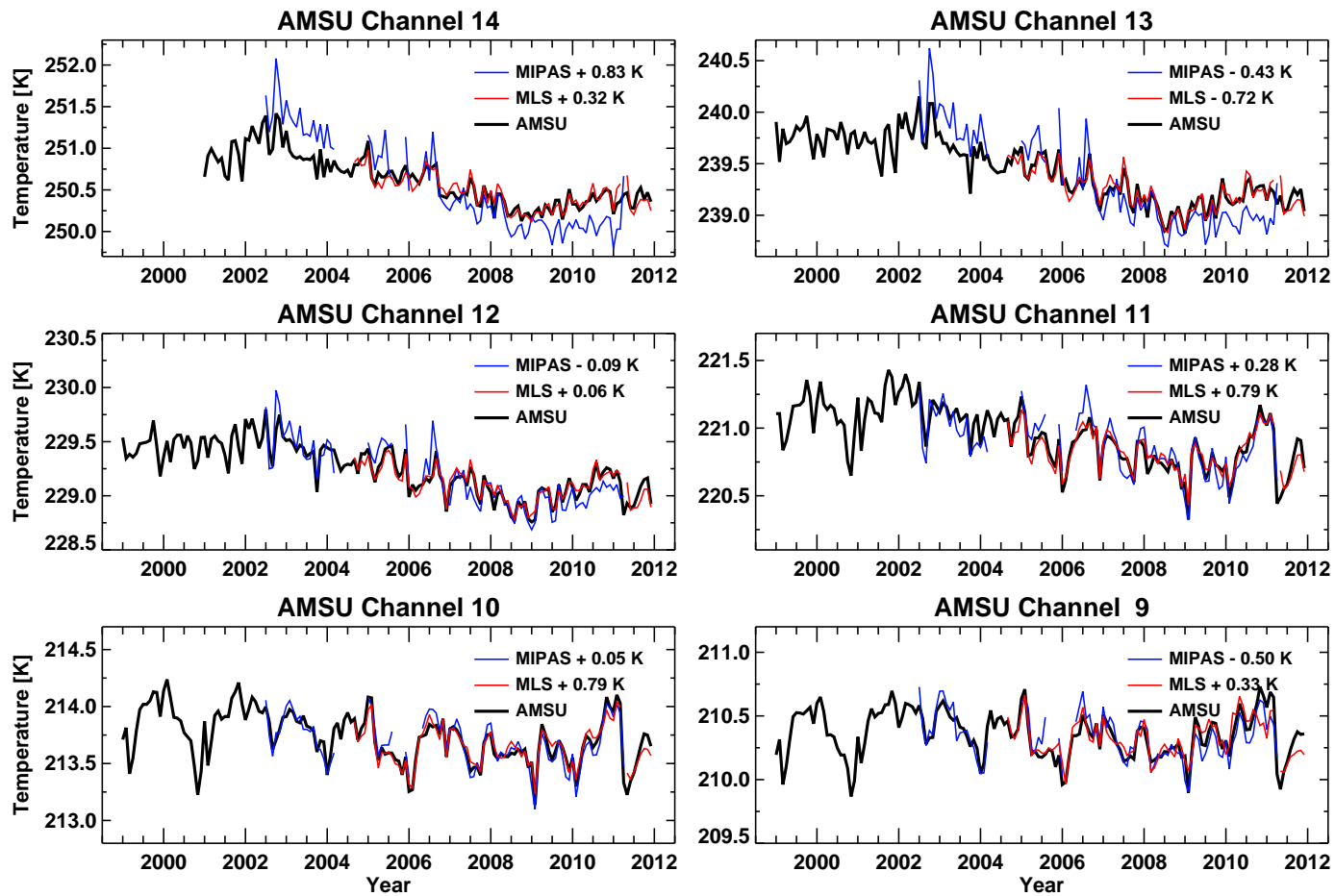

Figure 8. Deseasonalized temperatures for AMSU channels 9-14 (black) and the corresponding AMSU-weighted temperatures computed from MIPAS (blue) and MLS (red). The constant offsets between MIPAS and AMSU and between MLS and AMSU are labelled in each panel.
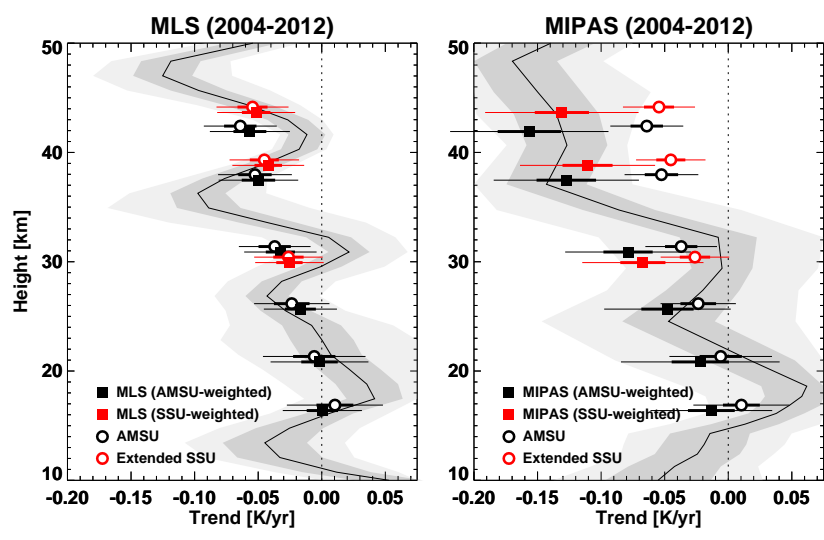

Figure 9. Linear temperature trends for MLS (left) and MIPAS (right) computed from 2004 to 2012. The solid curves are computed from the height-dependent data; the black and red squares are the corresponding AMSU-weighted and SSU-weighted results plotted at the heights of the weighting function maxima shown in Fig. 1 and offset slightly in the vertical for clarity. The black and red circles are the corresponding trends from AMSU and extended SSU. The channel numbers range from 14 (3) at the top to 9 (1) at the bottom for AMSU (SSU). The dark- and light-grey shading, as well as the thick and thin error bars, denote the $95 \%$ confidence levels computed assuming, respectively, independent and serially correlated data; see text for details. malizing the weighting functions to have a vertical integral of unity over the data height range. As explained in Sect. 2.6 (see also Table 1), the CMIP5 models with poor vertical resolution in the stratosphere are not projected onto all three SSU channels, which explains why more grey curves are present in the bottom panel than in the top panel. The agreement between the CMIP5 multi-model mean (black) and extended SSU (red) is remarkably good. The good agreement from 1979 to 2006 has arisen, of course, because we are using version 2 of the NOAA SSU data. However, as noted earlier, Zou et al. (2014) did not compare SSU version 2 to models; here we do. After 2006 (the end of the SSU data record) the extended SSU temperatures also compare favourably with the CMIP5 models, with both exhibiting continued stratospheric cooling followed by warming starting in about 2009 . The cooling is due to a combination of the effects of increasing $\mathrm{CO}_{2}$ and the declining phase of the previous solar cycle, while the warming is presumably due to the current solar cycle, which commenced in 2008. Note that the CMIP5 RCP simulations included a solar cycle by repeating the last solar cycle (1996-2008) into the future.

Figure 10 compares the long-term temperature trends for extended SSU and the CMIP5 models (1980-2012; left) and for extended SSU and the CCMVal2 models (1980 2005; right). For 1980-2012 the trends for extended SSU are $-0.63 \pm 0.13,-0.71 \pm 0.15$ and $-0.80 \pm 0.17 \mathrm{~K} \mathrm{decade}^{-1}$ for channels 1, 2 and 3, respectively. The $95 \%$ uncertain- 
ties, which are computed the same way as in Fig. 9, take into account serial correlation. The extended SSU cooling trends for 1980 to 2005 are $\sim 9 \%$ larger than those for 1980-2012 for channel 1 and $\sim 15 \%$ larger for channels 2 and 3 . This reflects the much weaker cooling rate over the second half compared with the first half of the extended record. In all cases, the SSU-weighted model trends (squares) agree with the observed trends within the uncertainties (error bars). The cooling increases with increasing altitude for both the models and the observations. Although the channel 3 extended SSU trend is considerably weaker than the CCMVal2 trend profile at the altitudes where the weighting function peaks $(\sim 44 \mathrm{~km})$, the channel $3 \mathrm{CCMVal} 2$ trend is entirely consistent with the extended SSU trend. This difference between the weighted and profile trend is due to the large curvature in the profile trend. This illustrates why nadir measurements should never be directly compared with profile measurements. For the CMIP5 models the curvature of the profile trend is much weaker than for the CCMVal2 models, which explains why the weighted and profile trends are in much closer agreement. The lack of strong cooling above $\sim 40 \mathrm{~km}$ in the CMIP5 models is presumably a result of coarser stratospheric resolution and lower upper boundaries than the CCMVal2 models, which also have more comprehensive physical parameterizations for the middle atmosphere.

Figure 11 shows near-global-mean temperature differences for extended SSU and the CCMVal2 multi-model means for the period of strong ozone depletion (1986-1995; left) and the start of ozone recovery (1995-2004; right). (Note that for these periods, the merging is irrelevant and the comparison is basically with the version 2 NOAA SSU record itself.) We prefer differences to linear trends for this purpose because of the highly nonlinear time evolution. To minimize the impact of solar variability, which clearly has a large modulating effect on the long-term cooling (e.g. Fig. 7), we compare the two recent decadal periods between solar minima. For extended SSU, distinct cooling of about $-0.7 \mathrm{~K}$ is seen at all levels over 1986-1995, whereas negligible cooling is found over 1995-2004. This highlights the important role of ozone depletion in the observed stratospheric cooling up to the mid-1990s. A similar though somewhat less pronounced contrast between the two periods is seen in the temperature differences from the models.

\section{Conclusions}

We present a physically based method for merging nearglobal-mean brightness temperatures from SSU and AMSU using measurements from a third instrument, in this case MIPAS, which has high enough vertical resolution that it can sufficiently accurately simulate the vertically weighted temperatures of both SSU and AMSU. The SSU temperatures are expressed as a linear combination of AMSU tempera-
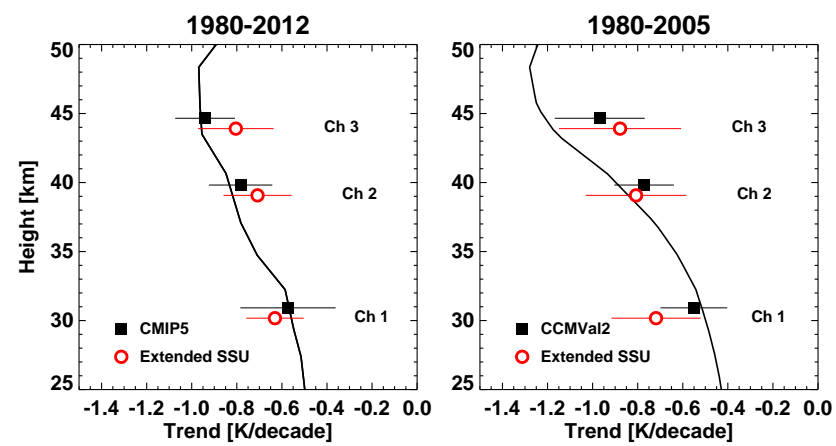

Figure 10. Temperature trends for extended SSU and the CMIP5 multi-model mean for 1980-2012 (left) and extended SSU and the CCMVal2 multi-model mean for 1980-2005 (right). The trend profiles and weighted trends for the models are given by the lines and squares. The latter are plotted at the heights of the maxima of the three SSU weighting functions; for clarity the symbols for the models are offset slightly with respect to extended SSU. The error bars denote the $95 \%$ confidence levels.
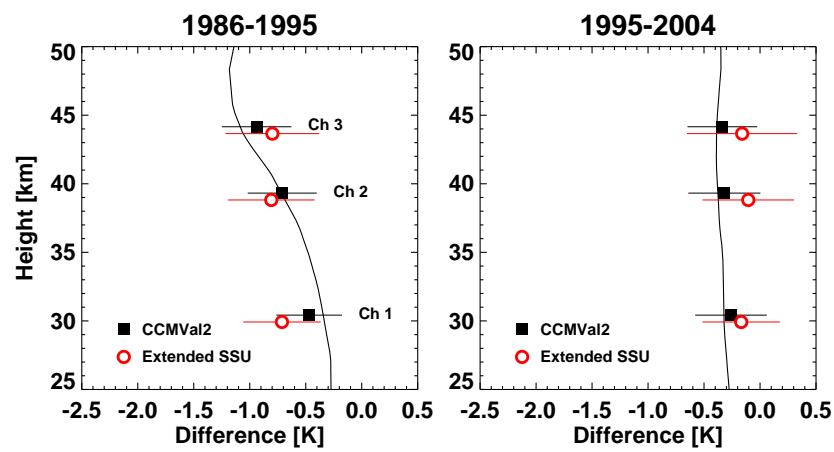

Figure 11. Temperature differences for extended SSU and the CCMVal2 multi-model mean for 1986-1995 (left) and 1995-2004 (right). The CCMVal2 temperature difference profiles are given by the black curves, the SSU-weighted CCMVal2 differences by the black squares and the extended SSU differences by the open circles. The latter two are plotted at the heights of the maxima of the three SSU weighting functions, ranging from channel 3 at the top to channel 1 at the bottom; the symbols are offset slightly in the vertical for clarity. The error bars denote the $95 \%$ confidence levels. The differences are computed from data that have been averaged over 2 years spanning each of the two end points.

tures, with the coefficients determined by fitting the AMSU weighting functions to the SSU weighting functions. The MIPAS data are used in matching the SSU temperatures and the AMSU-simulated SSU temperatures.

Multiple linear regression does not work for merging the SSU and AMSU temperatures because the AMSU channels are not sufficiently linearly independent (in a statistical sense) and thus the determination of the regression coefficients is underconstrained. Part of the correlation between the channels arises from the overlap of the weighting func- 
tions, but part reflects strong vertical relationships in the variability of global-mean temperature.

The relative bias between SSU and the AMSU-simulated SSU channels is expressed as a sum of three relative biases: between SSU and MIPAS, between the SSU channels and the AMSU-simulated SSU channels (both applied to MIPAS data), and between MIPAS and AMSU. In this way, MIPAS is used as a transfer function between SSU and AMSU.

In this particular case, SSU and AMSU overlap in time and so a transfer function is not strictly required, but our method would be applicable in cases where the two data sets to be merged did not overlap in time, so long as there was a higher-resolution data set that bridged between them. Also, this method allows for quantification of the error incurred by the approximation of the SSU weighting functions by the AMSU weighting functions.

MIPAS was found to track the three SSU channels and the six AMSU channels very well in time, especially in their seasonal cycle. This provides well-defined relative biases between MIPAS and the two nadir instruments, allowing for the merging of the two nadir records to be performed with confidence. In particular, the standard deviation of the differences during the overlap period is less than $0.1 \mathrm{~K}$ for all three SSU channels, which is much less than the dynamic range of the time series. Thus, uncertainties in the merging make only a very small contribution to the uncertainties in the long-term changes. The relative bias that results from imperfect approximation of the SSU weighting functions by the AMSU weighting functions is a significant contributor to the overall relative bias for SSU channels 1 and 2, and the dominant contributor for channel 3. Although the relative bias for channel 3 seems stable over the overlap period (e.g. the correlation coefficient between SSU channel 3 and the AMSUsimulated channel 3 is 0.895 ), it does introduce a potential systematic uncertainty into the extension of SSU channel 3 into the future using AMSU.

The coefficients $\beta_{m}$ and relative biases $c_{n}$ developed here can be used to continuously extend the NOAA version $2 \mathrm{SSU}$ record forward in time using AMSU, as the AMSU record lengthens.

The near-global-mean linear temperature trends for the extended SSU data set for 1980-2012 are $-0.63 \pm 0.13$, $-0.71 \pm 0.15$ and $-0.80 \pm 0.17 \mathrm{~K} \mathrm{decade}^{-1}$ for channels 1,2 and 3 , respectively. These trends are in agreement with those from CMIP5 model simulations over this period.

Because global-mean temperature exhibits relatively little interannual variability, compared to the temperature in particular latitude bands, trends can be determined with confidence even over relatively short records. We analyse trends over the period 2004-2012 when data from a second vertically resolved temperature data set, Aura MLS, are available. While MLS temperature trends are essentially identical to those of AMSU, the current version of MIPAS data shows a cooling trend relative to AMSU, which is in agreement with preceding drift analyses (Eckert, 2012). This does not compromise the use of MIPAS as a transfer function between SSU and AMSU, because the relative biases are computed for a particular period, nor for the use of MIPAS data to examine seasonal cycles and interannual variability. However, this version of MIPAS temperature should not be used to determine long-term trends. On the other hand, the high level of agreement between MLS and AMSU provides confidence in both data sets for trend analysis. Over the 20042012 period these data show a statistically significant cooling ranging from $\sim 0.6 \pm 0.3 \mathrm{~K} \mathrm{decade}^{-1}$ for channel 14 to $\sim 0.3 \pm 0.2 \mathrm{~K} \mathrm{decade}^{-1}$ for channel 12 , and no statistically significant change for the three lowest channels 9, 10 and 11 .

It is worth noting that even the narrower weighting functions that characterize the AMSU channels, relative to the deeper weighting functions of the SSU channels, strongly smooth the vertical structure seen in the MLS trends. Thus, nadir measurements should never be compared with profile trends derived from higher-vertical-resolution instruments or models; the latter must always be first filtered through the weighting functions of the nadir measurements.

The long-term stratospheric near-global-mean temperature record since 1979, which is represented by the SSU channels, exhibits considerable temporal structure associated with cooling from increasing $\mathrm{CO}_{2}$ and from ODS-induced ozone depletion, the effects of the solar cycle, and warming from volcanic eruptions. Version 2 of the NOAA SSU record is found to be consistent with the behaviour seen in model simulations. This is in contrast to the findings of Thompson et al. (2012), who examined version 1 of those data. In particular, the (extended) SSU record and the CCMVal2 models show the same contrast in cooling trends between the ozone depletion and recovery periods, with weak cooling over 1995-2004 compared with the large cooling seen in the period 1986-1995 of strong ozone depletion. The extended SSU data show a continued cooling beyond the end of the SSU record, with a small warming in the last few years (up to 2011) which is presumably associated with the solar cycle. Both features are consistent with the high-top CMIP5 models. Thus, the extended SSU global-mean temperature record constructed here, which covers 1979-2012, is consistent with physical expectations of the vertical structure and temporal variations in the rates of stratospheric cooling over this period.

Acknowledgements. Funding for C. McLandress and A. I. Jonsson was provided from the European Space Agency. The authors thank Gloria Manney for providing the Aura MLS data and also for helpful discussions. C. McLandress thanks David Plummer for providing some diagnostic code. The two anonymous reviewers are thanked for their constructive comments.

Edited by: Q. Fu 


\section{References}

Christy, J. R., Spencer, R. W., Norris, W. B., Braswell, W. D., and Parker, D. E.: Error estimates of version 5.0 of MSU-AMSU bulk atmospheric temperatures, J. Atmos. Ocean. Tech., 20, 613629, 2003.

Dee, D. P., Uppala, S. M., Simmons, A. J., Berrisford, P., Poli, P., Kobayashi, S., Andrae, U., Balmaseda, M. A., Balsamo, G., Bauer, P., Bechtold, P., Beljaars, A. C. M., van de Berg, L., Bidlot, J., Bormann, N., Delsol, C., Dragani, R., Fuentes, M., Geer, A. J., Haimberger, L., Healy, S. B., Hersbach, H., Hólm, E. V., Isaksen, L., Kållberg, P., Köhler, M., Matricardi, M., McNally, A. P., Monge-Sanz, B. M., Morcrette, J.-J., Park, B.-K., Peubey, C., de Rosnay, P., Tavolato, C., Thépaut, J. N., and Vitart, F.: The ERA-Interim reanalysis: configuration and performance of the data assimilation system, Q. J. Roy. Meteor. Soc., 137, 553-597, doi:10.1002/qj.828, 2011.

Eckert, E.: Drifts and Trends in MIPAS Temperature and Ozone Measurements, Diplomarbeit, Karlsruhe Institute of Technology, Karlsruhe, 2012.

Eckert, E., von Clarmann, T., Kiefer, M., Stiller, G. P., Lossow, S., Glatthor, N., Degenstein, D. A., Froidevaux, L., GodinBeekmann, S., Leblanc, T., McDermid, S., Pastel, M., Steinbrecht, W., Swart, D. P. J., Walker, K. A., and Bernath, P. F.: Drift-corrected trends and periodic variations in MIPAS IMK/IAA ozone measurements, Atmos. Chem. Phys., 14, 25712589, doi:10.5194/acp-14-2571-2014, 2014.

Fischer, H., Birk, M., Blom, C., Carli, B., Carlotti, M., von Clarmann, T., Delbouille, L., Dudhia, A., Ehhalt, D., Endemann, M., Flaud, J. M., Gessner, R., Kleinert, A., Koopman, R., Langen, J., López-Puertas, M., Mosner, P., Nett, H., Oelhaf, H., Perron, G., Remedios, J., Ridolfi, M., Stiller, G., and Zander, R.: MIPAS: an instrument for atmospheric and climate research, Atmos. Chem. Phys., 8, 2151-2188, doi:10.5194/acp-8-2151-2008, 2008.

Fomichev, V. I: The radiative energy budget of the middle atmosphere and its parameterization in general circulation models, J. Atmos. Sol.-Terr. Phy., 71, 1577-1585, 2009.

Hegglin, M. I., Tegtmeier, S., Anderson, J., Froidevaux, L., Fuller, R., Funke, B., Jones, A., Lingenfelser, G., Lumpe, J., Pendlebury, D., Remsberg, E., Rozanov, A., Toohey, M., Urban, J., von Clarmann, T., Walker, K. A., Wang, R., and Weigel, K.: SPARC Data Initiative: Comparison of water vapor climatologies from international satellite limb sounders, J. Geophys. Res., 118, 1182411846, doi:10.1002/jgrd.50752, 2013.

Hegglin, M. I., Plummer, D. A., Shepherd, T. G., Scinocca, J. F., Anderson, J., Froidevaux, L., Funke, B., Hurst, D., Rozanov, A., Urban, J., von Clarmann, T., Walker, K. A., Wang, H. J., Tegtmeier, S., and Weigel, K.: Vertical structure of stratospheric water vapour trends derived from merged satellite data, Nature Geosci., 7, 768-776, 2014.

IPCC (Intergovernmental Panel on Climate Change): Climate Change 2013: The Physical Scientific Basis, edited by: Stocker, T. F., Qin, D., Plattner, G.-K., Tignor, M., Allen, S. K., Boschung, J., Nauels, A., Xia, Y., Bex, V., and Midgley, P. M., Cambridge University Press, New York, 1535 pp., 2013.

Livesey, N. J., Read, W. G., Froideveaux, L., Lambert, A., Manney, G. L., Pumphrey, H. C., Santee, M. L., Schwartz, M. J., Wang, S., Cofield, R. E., Cuddy, D. T., Fuller, R. A., Jarnot, R. F., Jiang, J. H., Knosp, B. W., Stek, P. C., Wagner, P. A., and Wu, D. L.: Version 3.3 Level 2 data quality and description document. Tech.
Rep. JPL D-33509, Jet Propulsion Laboratory, available at: http: //mls.jpl.nasa.gov (last access: 17 August 2015), 2011.

McLandress, C., Plummer, D. A., and Shepherd, T. G.: Technical Note: A simple procedure for removing temporal discontinuities in ERA-Interim upper stratospheric temperatures for use in nudged chemistry-climate model simulations, Atmos. Chem. Phys., 14, 1547-1555, doi:10.5194/acp-14-1547-2014, 2014.

Mears, C. A. and Wentz, F. J.: Construction of the Remote Sensing Systems V3.2 atmospheric temperature records from the MSU and AMSU microwave sounders, J. Atmos. Ocean. Tech., 26, 1040-1056, 2009.

Morgenstern, O., Giorgetta, M. A., Shibata, K., Eyring, V., Waugh, D. W., Shepherd, T. G., Akiyoshi, H., Austin, J., Baumgaertner, A. J. G., Bekki, S., Braesicke, P., Brühl, C., Chipperfield, M. P., Cugnet, D., Dameris, M., Dhomse, S., Frith, S. M., Garny, H., Gettelman, A., Hardiman, S. C., Hegglin, M. I., Jöckel, P., Kinnison, D. E., Lamarque, J.-F., Mancini, E., Manzini, E., Marchand, M., Michou, M., Nakamura, T., Nielsen, J. E., Olivié, D., Pitari, G., Plummer, D. A., Rozanov, E., Scinocca, J. F., Smale, D., Teyssèdre, H., Toohey, M., Tian, W., and Yamashita, Y.: Review of the formulation of present-generation stratospheric chemistryclimate models and associated external forcings, J. Geophys. Res., 115, D00M02, doi:10.1029/2009JD013728, 2010.

Nash, J. and Saunders, R.: A review of Stratospheric Sounding Unit radiance observations for climate trends and reanalyses, Q. J. Roy. Meteor. Soc., doi:10.1002/qj.2505, 2015.

Randel, W. J., Shine, K. P., Austin, J., Barnett, J., Claud, C., Gillett, N. P., Keckhut, P., Langematz, U., Lin, R., Long, C., Mears, C., Miller, A., Nash, J., Seidel, D. J., Thompson, D. W. J., Wu, F., and Yoden, S.: An update of observed stratospheric temperature trends, J. Geophys. Res., 114, D02107, doi:10.1029/2008JD010421, 2009.

Santer, B. D., Wigley, T. M. L., Boyle, J. S., Gaffen, J. S., Hnilo, J. J., Nychka, D., Parker, D. E., and Taylor, K. E., Statistical significance of trends and trend differences in layer-average atmospheric time series, J. Geophys. Res., 105, 7337-7356, 2000.

Schwartz, M. J., Lambert, A., Manney, G. L., Read, W. G., Livesay, N. J., Froideveaux, L., Ao, C. O., Bernath, P. F., Boone, C. D., Cofield, R. E., Daffer, W. H., Drouin, B. J., Fetzer, E. J., Fuller, R. A., Jarnot, R. F., Jiang, J. H., Jiang, Y. B., Knosp, B. W., Krüger, K., Li, J.-L. F., Mlynczak, M. G., Pawson, S., Russell III, J. M., Santee, M. L., Synder, W. V., Stek, P. C., Thurstans, R. P., Tompkins, A. M., Wagner, P. A., Walker, K. A., Waters, J. W., and Wu, D. L.: Validation of the Aura Microwave Limb Sounder temperature and geopotential height measurements, J. Geophys. Res., 113, D15S11, doi:10.1029/2007JD008783, 2008.

Shepherd, T. G. and Jonsson, A. I.: On the attribution of stratospheric ozone and temperature changes to changes in ozonedepleting substances and well-mixed greenhouse gases, Atmos. Chem. Phys., 8, 1435-1444, doi:10.5194/acp-8-1435-2008, 2008.

Shine, K. P., Bourqui, M. S., de Forster, P. M., Hare, S. H. E., Langematz, U., Braesicke, P., Grewe, V., Ponater, M., Schnadt, C., Smith, C. A., Haigh, J. D., Austin, J., Butchart, N., Shindell, D. T., Randel, W. J., Nagashima, T., Portmann, R. W., Solomon, S., Seidel, D. J., Lanzante, J., Klein, S., Ramaswamy, V., and Schwartzkopf, M. D.: A comparison of model-simulated trends in stratospheric temperatures, Q. J. R. Meteor. Soc., 129, 15651588, doi:10.1256/qj.02.186, 2003. 
Solomon, S., Rosenlof, K. H., Portmann, R. W., Daniel, J. S., Davis, S. M., Sanford, T. J., and Plattner, G.-K.: Contributions of stratospheric water vapor changes to decadal variation in the rate of global warming, Science, 327, 1219-1222, 2010.

Stiller, G. P., Kiefer, M., Eckert, E., von Clarmann, T., Kellmann, S., García-Comas, M., Funke, B., Leblanc, T., Fetzer, E., Froidevaux, L., Gomez, M., Hall, E., Hurst, D., Jordan, A., Kämpfer, N., Lambert, A., McDermid, I. S., McGee, T., Miloshevich, L., Nedoluha, G., Read, W., Schneider, M., Schwartz, M., Straub, C., Toon, G., Twigg, L. W., Walker, K., and Whiteman, D. N.: Validation of MIPAS IMK/IAA temperature, water vapor, and ozone profiles with MOHAVE-2009 campaign measurements, Atmos. Meas. Tech., 5, 289-320, doi:10.5194/amt-5-289-2012, 2012.

Thompson, D. W. J., Seidel, D. J., Randel, W. J., Zou, C.-Z., Butler, A. H., Mears, C., Osso, A., Long, C., and Lin, R.: The mystery of recent stratospheric temperature trends, Nature, 491, 692-697, doi:10.1038/nature11579, 2012.

von Clarmann, T., Glatthor, N., Grabowski, U., Höpfner, M., Kellmann, S., Kiefer, M., Linden, A., Mengistu Tsidu, G., Milz, M., Steck, T., Stiller, G. P., Wang, D. Y., Fischer, H., Funke, B., Gil-López, S., and López-Puertas, M.: Retrieval of temperature and tangent altitude pointing from limb emission spectra recorded from space by the Michelson Interferometer for Passive Atmospheric Sounding (MIPAS), J. Geophys. Res., 108, doi:10.1029/2003JD003602, 2003.

von Clarmann, T., Höpfner, M., Kellmann, S., Linden, A., Chauhan, S., Funke, B., Grabowski, U., Glatthor, N., Kiefer, M., Schieferdecker, T., Stiller, G. P., and Versick, S.: Retrieval of temperature, $\mathrm{H}_{2} \mathrm{O}, \mathrm{O}_{3}, \mathrm{HNO}_{3}, \mathrm{CH}_{4}, \mathrm{~N}_{2} \mathrm{O}, \mathrm{ClONO}_{2}$ and $\mathrm{ClO}$ from MIPAS reduced resolution nominal mode limb emission measurements, Atmos. Meas. Tech., 2, 159-175, doi:10.5194/amt-2-159-2009, 2009.
Wang, L. and Zou, C.-Z.: AMSU-A-Only atmospheric temperature data records from the lower troposphere to the top of the stratosphere, J. Atmos. Ocean. Tech., 31, 808-825, doi:10.1175/JTECH-D-13-00134.1, 2014.

Wang, D. Y., von Clarmann, T., Fischer, H., Funke, B., Gil-López, S., Glatthor, N., Grabowski, U., Höpfner, M., Kaufmann, M., Kellmann, S., Kiefer, M., Koukouli, M. E., Linden, A., LópezPuertas, M., Mengistu Tsidu, G., Milz, M., Steck, T., Stiller, G. P., Simmons, A. J., Dethof, A., Swinbank, R., Marquardt, C., Jiang, J. H., Romans, L. J., Wickert, J., Schmidt, T., Russell III, J., and Remsberg, E.,: Validation of stratospheric temperatures measured by Michelson Interferometer for Passive Atmospheric Sounding (MIPAS) on Envisat, J. Geophys. Res., 110, D08301, doi:10.1029/2004JD005342, 2005.

Wang, L., Zou, C.-Z., and Qian, H.: Construction of stratospheric temperature data records from Stratospheric Sounding Units, J. Climate, 25, 2931-2946, doi:10.1175/JCLI-D-11-00350.1, 2012.

Wickert, J., Reigber, C., Beyerle, G., König, R., Marquardt, C., Schmidt, T., Grunwaldt, L., Galas, R., Meehan, T. K., Melbourne, W. G., and Hocke, K.: Atmosphere sounding by GPS radio occultation: First results from CHAMP, Geophys. Res. Lett., 28, 3263-3266, 2001.

WMO (World Meteorological Organization): Scientific Assessment of Ozone Depletion: 2014, World Meteorological Organization, Global Ozone Research and Monitoring Project - Report No. 55, 416 pp., Geneva, Switzerland, 2014.

Zou, C.-Z., Qian, H., Wang, W., Wang, L., and Long, C.: Recalibration and merging of SSU observations for stratospheric temperature trend studies, J. Geophys. Res., 119, 13180-13205, doi:10.1002/2014JD021603, 2014. 